\title{
Densidades de semeadura e safras de cultivo no desempenho produtivo de cultivares de feijoeiro-comum
}

\section{Seeding rates and seasons of cultivation on growth performance of cultivars of common bean}

\author{
Marcos Gleidson Pereira dos Santos ${ }^{1 *}$; Abner José de Carvalho²; \\ Andréia Márcia Santos de Souza David²; Hugo Tiago Ribeiro Amaro ${ }^{1}$; \\ Neiva Maria Batista Vieira33; Vanet Batista de Souza ${ }^{4}$; José Eustáquio de Souza \\ Carneiro $^{5}$
}

Resumo

Embora existam outros aspectos relacionados, como clima, solo e manejo da cultura, o hábito de crescimento da cultivar é um dos principais fatores envolvidos na resposta do feijoeiro à densidade de semeadura. Para tanto, o emprego de densidade de semeadura adequada é fator fundamental à obtenção de melhores respostas tecnológicas que resultem em maiores produtividades de grãos na cultura do feijão. Com o objetivo de estudar os efeitos de densidades de semeadura e safras de cultivo sobre o rendimento de grãos e componentes primários de rendimento de cultivares de feijoeiro, foi conduzido um experimento nas safras da seca e de inverno. Os tratamentos foram dispostos em esquema fatorial $4 \times 5$, envolvendo quatro cultivares de feijoeiro (Ouro Vermelho, Ouro Negro, Madrepérola e Manteigão Vermelho) e cinco densidades de semeadura (100, 200, 300, 400 e 500 mil plantas ha-1). Em ambas as safras, o delineamento experimental utilizado foi o de blocos casualizados, com quatro repetições. Por ocasião da colheita foi avaliado o estande final, o rendimento de grãos e os componentes primários (número de vagens por planta, número de grãos por vagem e massa de cem grãos). Realizou-se análise de variância conjunta para safras, e os efeitos de densidade de semeadura foram submetidos à análise de regressão, já os efeitos de cultivares foram estudados pelo teste de Tukey e os de safras pelo teste $\mathrm{F}$, a 1 e a 5\%. Com exceção do cultivar Ouro Negro cultivado na safra de inverno, em que o maior rendimento de grãos é obtido com população em torno de 300 mil plantas por hectare, o aumento na densidade de semeadura não interfere na produtividade do feijoeiro. Independentemente da densidade de semeadura, o feijoeiro cultivado na safra da seca apresenta maior número de grãos por vagem, maior massa média de cem grãos do que o cultivado na safra de inverno.

Palavras-chave: Técnicas culturais, Phaseolus vulgaris L., densidade de semeadura, rendimento

\footnotetext{
Abstract

While there are others aspects associated, such as climate, soil and crop management, the growth habit of the cultivar is one of the main factors involved in answer in gof common bean to sowing density.

${ }^{1}$ Eng $^{\text {os }}$ Agros , Mestres em Produção Vegetal, Discentes do Curso de Doutorado em Fitotecnia, Universidade Federal de Viçosa, UFV, Viçosa, MG. E-mail: gleidsonagron@yahoo.com.br; htiagoamaro@yahoo.com.br

2 Eng ${ }^{\text {os }}$ Agr $^{\text {os }}$, Profs. Drs., Dept ${ }^{\circ}$ de Ciências Agrárias da Universidade Estadual de Montes Claros, UNIMONTES, Montes Claros, MG. E-mail: abjocar@yahoo.com.br; andreiamssdavid@yahoo.com.br

${ }^{3}$ Eng $^{\mathrm{a}}$ Agr $^{\mathrm{a}}$, Prof $^{\mathrm{a}}$ Dr $^{\mathrm{a}}$, Instituto Federal de Educação, Ciência e Tecnologia do Sul de Minas Gerais, Machado, MG. E-mail: neivavieira2003@yahoo.com.br

${ }^{4}$ Enga Agra $^{\mathrm{a}}$ M.e em Produção Vegetal, UNIMONTES, Montes Claros, MG. E-mail: vanetbatista@yahoo.com.br

5 Eng $^{\circ}$ Agr $^{\circ}$, Prof. M.e do Dept ${ }^{\circ}$ de Fitotecnia, DFT/UFV, Viçosa, MG. E-mail: jesc@ufv.br

Autor para correspondência
} 
Thus, the use of appropriate seeding rate is critical to obtaining the best technological solutions that result inhigher grain yields in the common bean. With goal of estudy the effects of seeding density and seasons about yield of grains and primary components of yield of common bean cultivars, was conduced a experiment in the experimental farm of the UNIMONTES, in Janaúba, MG, in the dry seanson and winter season in the year of 2011. The treatments were arranged in factorial scheme $4 \times 5$, involving four cultivars of bean (Ouro Vermelho, Ouro Negro, Madrepérola e Manteigão Vermelho) and five seeding density $(100,200,300,400$ e 500 thousand plants ha-1). In both seasons, the experimental design utilized was randomized complete block, with four replications. At harvest was evaluated the final stand, yield of grains e primary components (number of pods by plant, number of grain by pod and mass of hundred grains). It was realized joint analysis of data for seasons of growth, and the effects of sowing density were subjected to regression analysis, however the effects of cultivars were studied by Tukey test and seasons by F test at 1and 5\%. With the exception of Ouro Negro, grown in the winter season, which the highest grain yield is obtained with sowing density around 300 thousand plants by hectare, the increase in density of seeding does not affect the yield of common bean under the conditions considered in this study. Irrespective of sowing density, the common bean cultivated in the dry season show a greater number of seeds by pod, greater average weight of hundred grains, than common bean grown in the winter season.

Key words: Techniques of yield, Phaseolus vulgaris L, sowing density, yield

\section{Introdução}

O Brasil se destaca atualmente como o maior produtor e consumidor de feijão-comum (Phaseolus vulgaris L), sendo que nas safras de 2013/2014 foram colhidos cerca de 3,45 milhões de toneladas (CONAB, 2013). O estado de Minas Gerais é o segundo maior produtor nacional, responsável por aproximadamente $19 \%$ da produção do país. A região Norte de Minas Gerais obteve no ano de 2013, a produção de 34,4 mil toneladas em uma área de 50 mil ha, produção que corresponde a $8 \%$ do total produzido no estado. No município de Janaúba, MG, no ano de 2013 a área cultivada com esta leguminosa foi de 370 ha, com produção de 190 toneladas e rendimento médio de $570 \mathrm{~kg} \mathrm{ha}^{-1}$ (IBGE, 2013).

A baixa produtividade nacional está relacionada com a baixa tecnificação da maior parte dos produtores, sendo realizada adubação inadequada, pouco ou nenhum controle de pragas, doenças e plantas daninhas e uso de cultivares pouco produtivas em densidades de semeadura inapropriadas.

Embora existam outros aspectos relacionados, como clima, solo e manejo da cultura, o hábito de crescimento da cultivar é um dos principais fatores envolvidos na resposta do feijoeiro à densidade de semeadura (SOUZA et al., 2008). Para tanto, o emprego de densidade de semeadura adequada é fator fundamental à obtenção de melhores respostas tecnológicas que resultem em maiores produtividades de grãos na cultura do feijão.

O cultivo do feijoeiro ocorre basicamente em duas épocas no estado de Minas Gerais,nas safras das "águas" (principalmente entre outubro e novembro) e da "seca" (segunda quinzena de fevereiro a segunda quinzena de março), tendo também uma terceira época de plantio, chamada de "plantio de outono" (semeadura entre abril a junho) (ARAÚJO; FERREIRA, 2006). Sendo este, um fator que influencia o rendimento de grãos do feijoeiro, devido as condições climáticas verificadas em cada época do ano, especialmente no que diz respeito à temperatura, umidade e precipitação e que interferem no crescimento e no desenvolvimento das plantas, na ocorrência de pragas e doenças, afetando assim a produtividade de grãos (SOUZA et al., 2008).

As épocas de cultivo do feijoeiro, podem influenciar as respostas à densidade de semeadura para as cultivares de diferentes hábitos de crescimento, pois havendo condições ambientais que favoreçam maior desenvolvimento vegetativo da cultura, a densidade de semeadura adotada deve ser menor, observando no entanto a resposta de cada tipo de crescimento quanto a plasticidade dos componentes de rendimento. 
Dessa forma, a estabilização do rendimento de grãos é proporcionada pela interdependência entre os componentes do rendimento, sendo a competição entre as plantas intensificada à medida que ocorrem limitações nos recursos ambientais disponíveis. Para Costa, Kohahi-Shibata e Colin (1983) a plasticidade dos componentes do rendimento apresentada por algumas cultivares de feijão, frente a diferentes condições ambientais, devido a variações no espaçamento e população de plantas, pode facilitar a manutenção de um nível mais estável do rendimento de grãos quando existir o efeito de compensação entre eles.

Em geral, espaçamentos entre 0,40 a0,60 $\mathrm{m}$ entre fileiras, com 10 a 15 plantas por metro proporcionam maior rendimento (EMBRAPA, 2014), correspondendo a populações entre 167 a 375 mil plantas ha-1 ${ }^{-1}$ Segundo Fancelli e Dourado Neto (2007) a recomendação para escolha de espaçamento na cultura do feijoeiro deve levar em consideração o tipo de hábito de crescimento da cultivar. Segundo esses autores, a densidade populacional indicada para cultivares de hábito de crescimento tipo I varia entre 230 a 270 mil plantas ha $^{-1}$; para cultivares do tipo II, de 190 a 240 mil plantas ha-1 e para cultivares do tipo III, 170 a 230 mil plantas ha-1.

O rendimento de grãos pode ser afetado pela densidade populacional, fato este relacionado ao hábito de crescimento da planta de feijoeiro (STONE; PEREIRA, 1994; SHIMADA; ARF; SÁ, 2000). Alguns trabalhos envolvendo o estudo da influência da densidade populacional em cultivares de diferentes hábitos de crescimento têm mostrado que há incremento de produtividade com o aumento de população até 500 mil plantas ha-1 (SOUZA et al., 2004; SILVA; LIMA; MENEZES, 2007). Todavia, outros trabalhos dessa mesma natureza não demonstraram diferença significativa entre as populações estudadas (ARF et al., 1996; VALÉRIO; ANDRADE; FERREIRA, 1999; HORN et al., 2000; JADOSKI et al., 2000; SOUZA et al., 2002). Alguns desses autores atribuem este resultado ao fato de que plantas supridas adequadamente, mesmo em menores populações, mantêm a produção por área igual às maiores populações quando a produção individual das plantas aumenta eficientemente para obter rendimento satisfatório.

Em geral, aumentos na população de plantas por área, em uma mesma cultivar, têm efeito no padrão de distribuição das vagens na planta (HORN et al., 2000). O número de vagens é o primeiro componente do rendimento a ser definido na fase reprodutiva, sendo mais facilmente afetado pelo aumento da população, devido ao ambiente de competição (ADAMS, 1967; ARF et al., 1996). Com raríssimas exceções (SILVA; LIMA; MENEZES, 2007), há redução desse componente em função do incremento de plantas ha ${ }^{-1}$ (VALÉRIO; ANDRADE; FERREIRA, 1999; JADOSKI et al., 2000; JAUER, et al., 2003; SOUZA et al., 2004), em cultivares de diferentes hábitos de crescimento.

Diferentemente do que ocorre com o número de vagens por planta, o número de grãos por vagem é mais influenciado pelas condições ambientais que pela população de plantas (ARF et al., 1996). Muitos estudos verificaram a ausência de diferença significativa desse componente do rendimento em função da densidade populacional de plantas (ARF et al., 1996; SHIMADA; ARF; SÁ, 2000; SOUZA et al., 2002; JAUER et al., 2003; SOUZA et al., 2004). Entretanto, existem trabalhos que encontraram decréscimo do número de grãos por vagem em função do incremento de população (VALÉRIO; ANDRADE; FERREIRA, 1999; JADOSKI et al., 2000). Segundo Goulden (1976), a competição por luz e fotoassimilados proporcionada pelo aumento da população de plantas do feijoeiro, pode ocasionar abortamento de flores e chochamento das vagens, com redução do número de sementes produzidas.

Os efeitos encontrados na literatura para massa de cem grãos são muito variáveis e bastante influenciados pela cultivar (RAMALHO; ABREU, 2006). Trata-se do componente do rendimento menos influenciado pela população de plantas 
(ADAMS, 1967; BENNETT; ADAMS; BURGA, 1977). A grande maioria dos trabalhos envolvendo este componente comprova esta afirmação (VALÉRIO; ANDRADE; FERREIRA, 1999; JADOSKI et al., 2000; JAUER et al., 2003; SILVA; LIMA; MENEZES, 2007). Entretanto, resultados encontrados por Buzetti et al. (1992) observaram aumento na massa de cem grãos com a redução da população de plantas, enquanto Stone e Pereira (1994) observaram o mesmo com o aumento do espaçamento entre linhas de cultivo.

Assim, o objetivo deste trabalho foi estudar os efeitos de diferentes densidades de semeadura sobre os componentes de rendimento e produtividade de quatro cultivares de feijoeiro-comum de diferenciados hábitos de crescimento, cultivadas em diferentes safras no Norte de Minas Gerais.

\section{Material e Métodos}

O experimento foi conduzido nas safras de Verão-outono (safra da seca), com semeadura em março de 2011, e de Inverno-primavera (safra de inverno), com semeadura em agosto de 2011, na Fazenda Experimental da Universidade Estadual de Montes Claros- UNIMONTES, em Janaúba, Norte de Minas Gerais.O solo das áreas experimentais foi classificado como Latossolo Vermelho eutrófico (EMBRAPA, 2006), cujas principais características químicas foram: $\mathrm{pH}$ em água: 5,4 e 5,3; $\mathrm{P}\left(\mathrm{mg} \mathrm{dm}^{-}\right.$ $\left.{ }^{3}\right): 7,3$ e 8,7 ; P-rem $\left(\mathrm{mg} \mathrm{dm}^{-3}\right): 33,1$ e 34,$5 ; \mathrm{K}$ (mg $\left.\mathrm{dm}^{-3}\right)$ : 164 e 96; Ca trocável $\left(\mathrm{cmol}_{\mathrm{c}} \mathrm{dm}^{-3}\right): 2,8$ e 4,1;
Mg trocável $\left(\mathrm{cmol}_{\mathrm{c}} \mathrm{dm}^{-3}\right): 0,7$ e 1,0; Al trocável $\left(\mathrm{cmol}_{\mathrm{c}} \mathrm{dm}^{-3}\right): 0,2$ e 0,$1 ; \mathrm{H}+\mathrm{Al}\left(\mathrm{cmol}_{\mathrm{c}} \mathrm{dm}^{-3}\right): 1,6 \mathrm{e}$ 1,6; S.B. $\left(\mathrm{cmol}_{\mathrm{c}} \mathrm{dm}^{-3}\right): 3,9$ e 5,3; $\mathrm{t}\left(\mathrm{cmolc} \mathrm{dm}^{-3}\right): 4,1 \mathrm{e}$ 5,4; T (cmolc dm $\left.{ }^{-3}\right): 5,6$ e 7,0; m(\%): 4 e 1,0; V (\%): 70,0 e 77,0; Matéria orgânica (dag kg-1): 2,2 e 1,7, respectivamente para as áreas utilizadas nas safras da seca e de inverno de 2011.

As ocorrências diárias de temperatura, umidade relativa e precipitação pluvial registrada, durante o período de condução dos ensaios, através da Estação Climatológica da Empresa de Pesquisa Agropecuária de Minas Gerais (EPAMIG), Nova Porteirinha, MG, estão apresentadas na Figura 1.

Os tratamentos foram dispostos em esquema fatorial $4 \times 5$, envolvendo quatro cultivares de feijoeiro-comum de diferentes hábitos de crescimento (Ouro Vermelho, Ouro Negro, BRSMG Madrepérola e Manteigão Vermelho) e cinco densidades de semeadura (100, 200, 300, 400 e 500 mil plantas ha $\left.\mathrm{a}^{-1}\right)$. O delineamento experimental foi o de blocos casualizados, com quatro repetições. As características dos cultivares analisados estão descritos na Tabela 1.

Cada parcela foi composta por 6 fileiras de feijoeiro com $5 \mathrm{~m}$ de comprimento cada uma, espaçadas de 0,5 m entre si, perfazendo área total de $15 \mathrm{~m}^{2}$. Por ocasião da colheita,duas fileiras centrais foram utilizadas para avaliação do rendimento e seus componentes primários. Assim a área útil das parcelas foi de $5 \mathrm{~m}^{2}$. 
Tabela 1. Principais características das cultivares de feijoeiro-comum estudadas. Janaúba, MG, 2011.

\begin{tabular}{lcccc}
\hline \multicolumn{1}{c}{ Características } & Ouro Vermelho & Ouro Negro & $\begin{array}{c}\text { BRSMG } \\
\text { Madrepérola }\end{array}$ & $\begin{array}{c}\text { Manteigão } \\
\text { Vermelho }\end{array}$ \\
\hline Grupo comercial & Vermelho & Preto & Carioca & Manteigão \\
Cor de grãos & vermelho & Preto & Rajado & Vermelho \\
Hábito de crescimento & tipo II/III & tipo III & tipo III & tipo II \\
Massa de 100 grãos & $24-26 \mathrm{~g}$ & $25-27 \mathrm{~g}$ & $24-25 \mathrm{~g}$ & $30-40 \mathrm{~g}$ \\
Porte & semiprostrado & prostrado & prostrado & Semi-ereto \\
Ciclo & médio & médio & médio & médio \\
\hline
\end{tabular}

Fonte: EPAMIG (2012); PAULA JÚNIOR et al. (2010); EMBRAPA (2011).

Figura 1. Variação diária das médias de temperatura (máxima, média e mínima), umidade relativa do ar e precipitação pluviométrica (dados fornecidos pela Empresa de Pesquisa Agropecuária de Minas Gerais - EPAMIG), Nova Porteirinha, MG, no período de janeiro a dezembro de 2011.
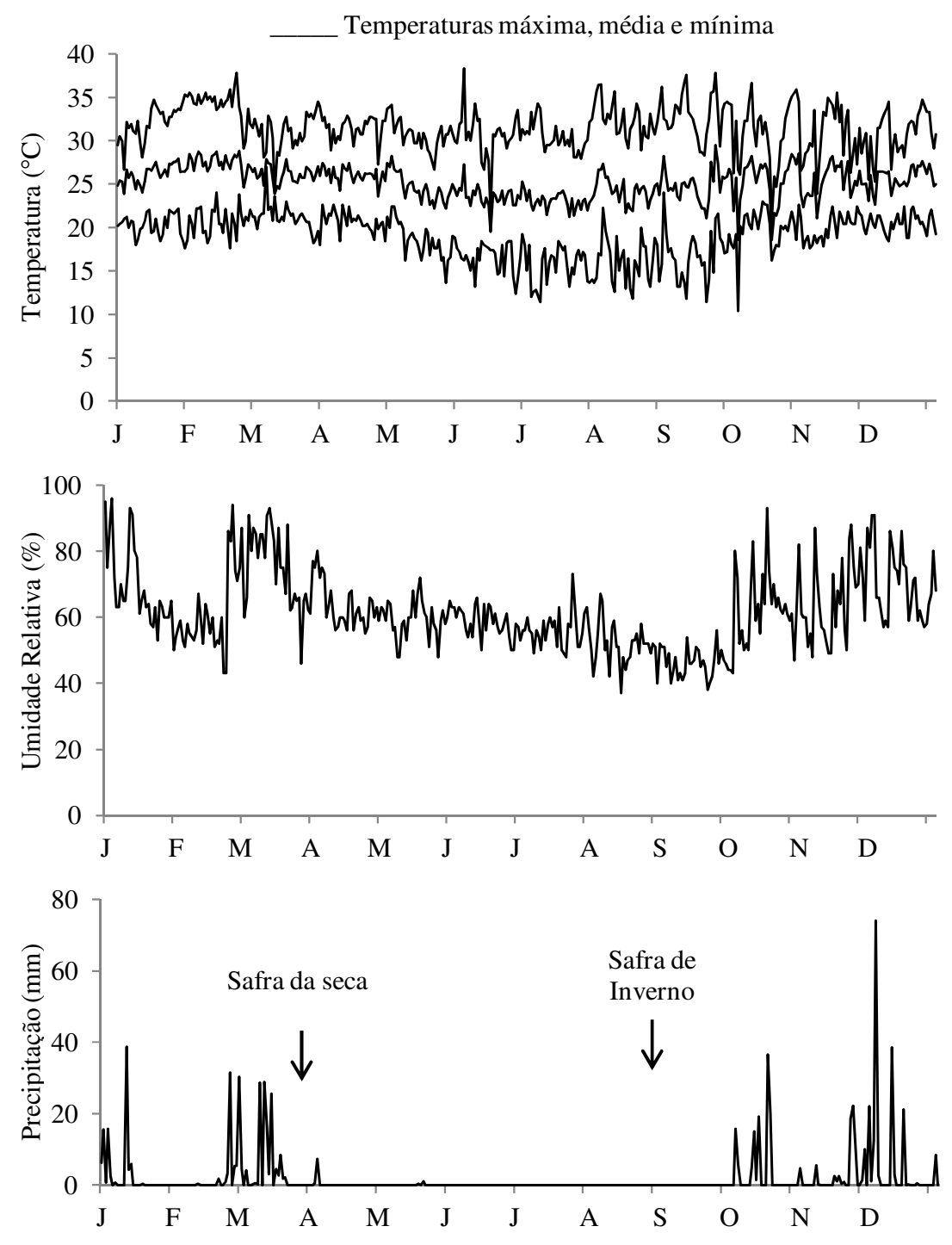

Fonte: Estação climatológica da EPAMIG. 
O preparo do solo foi convencional, constando de uma aração e duas gradagens em pré-semeadura. Com base nos resultados das análises químicas do solo, verificou-se a não necessidade de calagem. A adubação do feijoeiro também se baseou na interpretação destes resultados, considerando-se o nível tecnológico 3 (CHAGAS et al., 1999) e constou da aplicação de $375 \mathrm{~kg} \mathrm{ha}^{-1}$ da formulação 8-30-10 na semeadura, realizada mecanicamente com auxílio de semeadora- adubadora, mais 40 $\mathrm{kg} \mathrm{ha}^{-1}$ de $\mathrm{N}$ em cobertura no estádio V4, usando como fonte nitrogenada a uréia. Além disso, foi realizada uma aplicação via foliar de $80 \mathrm{~g} \mathrm{ha}^{-1}$ de molibdênio, utilizando o molibdato de sódio como fonte, também no estádio V4.

A semeadura foi feita manualmente, com uso de semeadoras manuais, adotando-se a densidade de semeadura ideal com auxílio de réguas de madeira de 5 metros, marcadas conforme cada densidade de plantas, pré-determinada pelos tratamentos. Foram semeadas duas sementes em cada ponto graduado da régua e posteriormente, por ocasião da emergência das plântulas foi realizado o desbaste.

Foram executadas todas as práticas fitossanitárias recomendadas à cultura para se evitar danos e perdas por pragas, doenças e plantas daninhas. A irrigação dos ensaios foi realizada via aspersão convencional com base na evapotranspiração da cultura, sendo obedecido um turno de rega de dois dias, para ambas as safras.

Por ocasião da colheita foram avaliados o estande final de plantas, o rendimento de grãos e seus componentes primários (número de vagens por planta, número de grãos por vagem e massa de 100 grãos). Para a avaliação do estande final foram contadas todas as plantas colhidas das fileiras centrais e o resultado foi transformado para plantas ha $^{-1}$. O número médio de vagens por planta e de grãos por vagem foram estimados a partir da contagem do total de vagens e grãos produzidos na área útil de cada parcela. A massa de 100 grãos foi estimada dividindo-se o peso total de grãos da parcela pelo seu respectivo número de grãos. $\mathrm{O}$ rendimento de grãos de feijão foi apurado pela pesagem da produção total da área útil da parcela. Tanto a massa média de 100 grãos, expresso em gramas, quanto o rendimento de grãos, expresso em $\mathrm{kg} \mathrm{ha}^{-1}$, foram corrigidos para $13 \%$ de umidade.

Os dados foram submetidos à análise de variância conjunta, envolvendo as duas safras estudadas. A análise conjunta das safras foi realizada mediante comparação do quadrado médio do erro da análise conjunta, de acordo com Banzato e Kronka (2006). Os efeitos das densidades de semeadura foram estudadas por análise de regressão, escolhendose os modelos adequados para representá-los em função do seu comportamento biológico, da significância do modelo e do valor do coeficiente de determinação( $\left.\mathrm{R}^{2}\right)$. Os efeitos das cultivares foram estudados pelo teste de Tukey a 1 e a $5 \%$, enquanto os efeitos das safras foram estudados pelo teste $\mathrm{F}$ a 1 e a $5 \%$.

\section{Resultados e Discussão}

A análise de variância conjunta das duas safras revelou efeito significativo da fonte de variação de cultivares $(\mathrm{Cv})$ sobre todas as características avaliadas. A densidade de semeadura (D) influenciou significativamente o estande final e o número de vagens por planta. As safras (S) influenciaram todas as variáveis, com exceção do estande final. A interação dupla $\mathrm{Cv}$ x D foi significativa para o número de vagens por planta e estande final, enquanto a interação $\mathrm{Cv}$ x $\mathrm{S}$ influenciou o número de vagens por planta, massa de cem grãos e o rendimento de grãos. A interação $\mathrm{D}$ x S foi significativa para o número de vagens por planta, enquanto a interação $\mathrm{Cv}$ x D x S, foi significativa para o número de vagens por planta e rendimento de grãos (Tabela 2).

O Manteigão Vermelho foi a cultivar que obteve o maior estande final de plantas, seguido dos cultivares Ouro Negro e Madrepérola que obtiveram médias intermediárias e por último o Ouro Vermelho, que 
obteve o menor estande final (Tabela 3). O menor estande final médio obtido em ambos cultivares pode ser devido à ocorrência de mortalidade de plantas por competição intraespecífica, pragas e doenças, bem como por condições edafoclimáticas desfavoráveis durante a condução dos ensaios à campo, demonstrando também que as cultivares menos propensas ao acamamento, como a cultivar
Manteigão Vermelho, são pouco influenciadas quanto a densidade população em relação a mortalidade de plantas, devido ao menor contato da parte aérea com o solo. Esse resultado é coerente e coincidente com os de vários estudos com o feijoeiro, como os de Valério, Andrade e Ferreira (1999); Souza et al. (2002); Alves et al. (2009).

Tabela 2. Resumo da análise de variância conjunta dos dados relativos a quatro cultivares de feijão cultivados em cinco densidades de plantio na época de plantio da seca e inverno. Janaúba, Minas Gerais, 2011.

\begin{tabular}{|c|c|c|c|c|c|c|c|c|c|c|}
\hline \multirow{3}{*}{$\begin{array}{c}\begin{array}{c}\text { Fontes de } \\
\text { variação }\end{array} \\
\text { Cultivar }(\mathrm{Cv})\end{array}$} & \multirow{3}{*}{$\begin{array}{r}\text { GL } \\
3\end{array}$} & \multicolumn{9}{|c|}{ Quadrados médios } \\
\hline & & Estande final & \multicolumn{2}{|c|}{$\begin{array}{l}\mathrm{N}^{\circ} \text { de vagens } \\
\text { por planta }\end{array}$} & \multicolumn{2}{|c|}{$\begin{array}{l}\mathrm{N}^{\circ} \text { de grãos } \\
\text { por vagem }\end{array}$} & \multicolumn{2}{|c|}{$\begin{array}{l}\text { Massa de cem } \\
\text { grãos }\end{array}$} & \multicolumn{2}{|c|}{$\begin{array}{l}\text { Rendimento de } \\
\text { grãos }\end{array}$} \\
\hline & & 11917 ** & 100,25 & $* *$ & 26,591 & $* *$ & 3273,6649 & $* *$ & 3454211,2 & $* *$ \\
\hline Densidade (D) & 4 & $387771 * *$ & 699,02 & $* *$ & 1,0634 & ns & 5,6712 & ns & 640284,69 & ns \\
\hline Safra $(\mathrm{S})$ & 1 & $1565 \mathrm{~ns}$ & 335,54 & $* *$ & 4,4206 & $* *$ & 591,4225 & $* *$ & 13784756 & $* *$ \\
\hline CV x D & 12 & $3852 \mathrm{~ns}$ & 12,93 & $*$ & 0,4124 & ns & 8,2031 & ns & 576117,01 & ns \\
\hline $\mathrm{CV} \times \mathrm{S}$ & 3 & $2261 \mathrm{~ns}$ & 23,47 & $*$ & 0,3542 & ns & 146,3845 & $* *$ & 1275632,7 & * \\
\hline $\mathrm{D} \times \mathrm{S}$ & 4 & $1469 \mathrm{~ns}$ & 22,80 & $* *$ & 0,2946 & ns & 1,0434 & ns & 299157,29 & ns \\
\hline$C V \times D \times S$ & 12 & $1318 \mathrm{~ns}$ & 20,04 & $* *$ & 0,3761 & ns & 4,22 & $\mathrm{~ns}$ & 713985,33 & * \\
\hline Bloco de safra & 6 & $1712 \mathrm{~ns}$ & 6,4386 & ns & 0,684697 & ns & 9,102402 & ns & 345766,41 & ns \\
\hline Erro & 114 & 3008 & 6,3772 & & 0,5815 & & 5,0713 & & 334939,33 & \\
\hline $\mathrm{CV} \%$ & & 22,27 & 22,91 & & 21,25 & & 8,65 & & 25,3 & \\
\hline
\end{tabular}

Não significativo (ns), significativo a $1 \%(* *)$ e a $5 \%(*)$ de probabilidade pelo teste $\mathrm{F}$.

Fonte: Elaboração dos autores.

Tabela 3. Valores médios de estande final de plantas para as cultivares de feijoeiro analisadas. Janaúba, MG, 2011.

\begin{tabular}{lc}
\hline Cultivar & Estande final (mil plantas ha $\left.\mathbf{~}^{-1}\right)$ \\
\hline Ouro Vermelho & $229,13 \mathrm{~b}$ \\
Ouro Negro & $244,13 \mathrm{ab}$ \\
Madrepérola & $241,86 \mathrm{ab}$ \\
Manteigão Vermelho & $270,27 \mathrm{a}$ \\
\hline
\end{tabular}

Médias seguidas de letras diferentes na coluna, diferem entre si pelo teste Tukey a 1\% de probabilidade.

Fonte: Elaboração dos autores.

O estande final de plantas cresceu de forma linear conforme se aumentou a densidade de semeadura (Figura 2). Entretanto como se observa na mesma figura, quanto maior foi a densidade de semeadura, maior foi a diferença entre o estande de plantas esperado e o estande de plantas final, o que certamente está relacionado com a maior mortalidade de plantas nas maiores densidades. Esse fato ocorre devido a maior competição intraespecífica, promovendo limitação dos recursos do solo, especialmente, água e luz (TAIZ; ZEIGER, 2013), bem como o favorecimento do desenvolvimento de doenças devido a formação de um microclima ideal para os patógenos (ANDRADE; RAMALHO, ABREU, 1992; ANDRADE et al., 2006). 
Figura 2. Estande final do feijoeiro (média de quatro cultivares e duas safras) em função das densidades populacionais. Janaúba, MG. 2011.

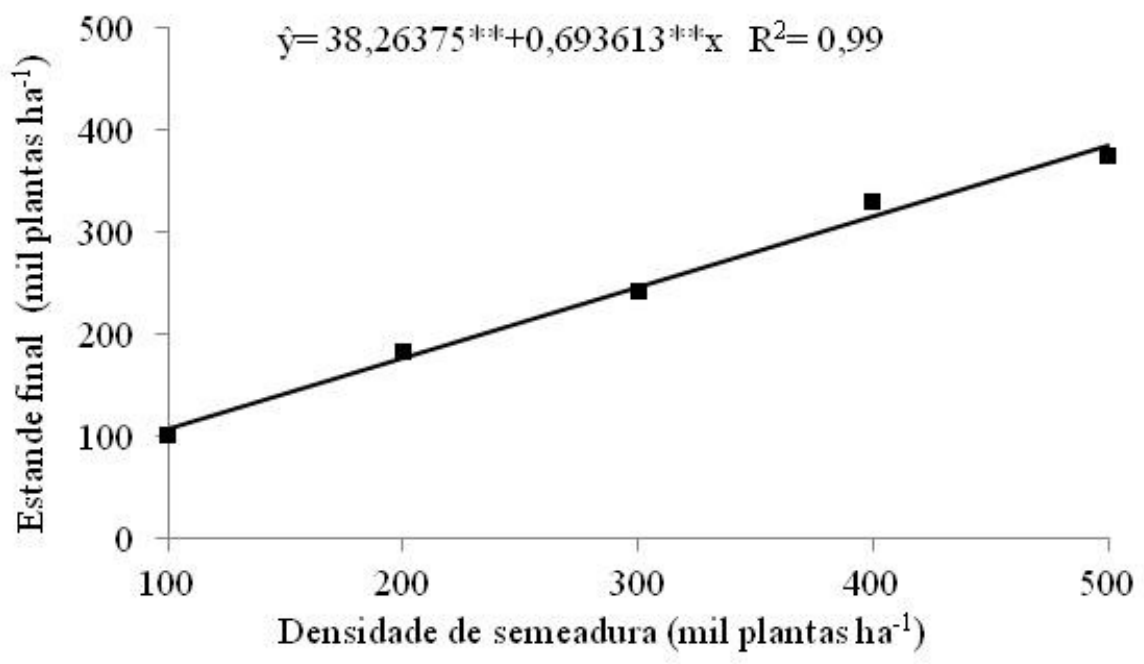

Fonte: Elaboração dos autores.

O desdobramento da interação $\mathrm{Cv} \times \mathrm{D}$ x $\mathrm{S}$, para os efeitos dos cultivares dentro de cada safra e densidade de semeadura, revelou que na safra da seca a cultivar Ouro Negro apresentou maior número de vagens em relação aos cultivares Ouro Vermelho nas densidades de 100 e 400 mil plantas ha $^{-1}$, em relação à Madrepérola na densidade de 200 mil plantas ha" ${ }^{-1}$, e em relação à Ouro Vermelho na densidade de 500 mil plantas ha ${ }^{-1}$. Já na safra de inverno, só houve diferenças significativas entre as cultivares na densidade de 300 mil plantas ha-1 em que a cultivar Ouro Vermelho apresentou maiores médias que os cultivares Madrepérola e Manteigão Vermelho, que, por sua vez, apresentaram maiores valores que a cultivar Ouro Vermelho (Tabela 4).

Tabela 4. Valores médios de número de vagens por planta de quatro cultivares de feijoeiro, em função da safra e de densidade de semeadura. Janaúba, MG. 2011.

\begin{tabular}{clcccc}
\hline \multirow{2}{*}{$\begin{array}{c}\text { Densidade } \\
\text { de semeadura }\end{array}$} & \multirow{2}{*}{ Safra } & \multicolumn{4}{c}{ Vagens por planta } \\
\cline { 3 - 5 } & & \multicolumn{4}{c}{ Cultivares } \\
\cline { 3 - 5 } & Seca & O. vermelho & O. Negro & Madrepérola & Manteigão \\
\hline \multirow{2}{*}{100} & $18 \mathrm{aB}$ & $26 \mathrm{aA}$ & $22 \mathrm{aAB}$ & $18 \mathrm{aB}$ \\
& Inverno & $16 \mathrm{aA}$ & $17 \mathrm{bA}$ & $16 \mathrm{bA}$ & $17 \mathrm{aA}$ \\
\hline \multirow{2}{*}{200} & Seca & $12 \mathrm{aAB}$ & $16 \mathrm{aA}$ & $11 \mathrm{aB}$ & $12 \mathrm{aAB}$ \\
& Inverno & $10 \mathrm{aA}$ & $10 \mathrm{bA}$ & $10 \mathrm{aA}$ & $13 \mathrm{aA}$ \\
\hline \multirow{2}{*}{300} & Seca & $8 \mathrm{aA}$ & $11 \mathrm{bA}$ & $10 \mathrm{aA}$ & $8 \mathrm{aA}$ \\
& Inverno & $4 \mathrm{bC}$ & $16 \mathrm{aA}$ & $10 \mathrm{aB}$ & $7 \mathrm{aBC}$ \\
\hline \multirow{2}{*}{400} & Seca & $8 \mathrm{aB}$ & $13 \mathrm{aA}$ & $10 \mathrm{aAB}$ & $8 \mathrm{aB}$ \\
& Inverno & $8 \mathrm{aA}$ & $5 \mathrm{bA}$ & $6 \mathrm{bA}$ & $5 \mathrm{aA}$ \\
\hline \multirow{2}{*}{500} & Seca & $7 \mathrm{aB}$ & $12 \mathrm{aA}$ & $11 \mathrm{aAB}$ & $7 \mathrm{aAB}$ \\
& Inverno & $5 \mathrm{aA}$ & $6 \mathrm{bA}$ & $5 \mathrm{bA}$ & $6 \mathrm{aA}$ \\
\hline
\end{tabular}

Dentro de cada fator, médias seguidas por diferentes letras diferem significativamente pelo teste $\mathrm{F}$ (safras) ou pelo teste de Tukey (Cultivares), a 1\% de probabilidade. Letras minúsculas comparam as safras, enquanto as maiúsculas comparam as cultivares.

Fonte: Elaboração dos autores. 
O estudo dos efeitos das safras dentro de cada cultivar e densidade de semeadura revelou que a cultivar Ouro Vermelho apresentou maior número de vagens por planta na safra da seca em relação à safra de inverno apenas na densidade de 300 mil plantas ha-1. Quanto a cultivar Ouro Negro, houve superioridade da safra da seca em relação a de inverno em todas as densidades de semeadura, exceto para a densidade de 300 mil plantas, em que na safra de inverno foi observado maior número de vagens por planta. Já para a cultivar Madrepérola foi observado diferença significativa das safras nas densidades de 100, 400 e 500 mil plantas ha${ }^{1}$, revelando-se superioridade da safra da seca em relação à de inverno. Constatou-se que não houve diferença significativa entre as safras em nenhuma das densidades de semeadura analisadas para a cultivar Manteigão Vermelho (Tabela 4).

$\mathrm{O}$ estudo da interação $\mathrm{Cv} \times \mathrm{D}$ x S, demonstrou que, o número de vagens por planta foi influenciado pelas safras.Notadamentenos cultivares Ouro Negro e Madrepérola, de hábito de crescimento prostrado (tipo III) e o Ouro Vermelho, cultivar de hábito de crescimento semi-prostrado (tipo II/III), não afetando o Manteigão Vermelho de hábito de crescimento tipo II (Tabela 4). Este resultado pode ser explicado pelo maior contato das plantas, flores e vagens de cultivares de hábito de crescimento tipo III e II/III no solo, favorecendo o abortamento de flores e deterioração de vagens principalmente na safra de inverno-primavera devido a ocorrência de altas temperaturas e excesso de chuvas concentradas após maturação fisiológica das plantas (Figura 1).

Alves et al. (2009) trabalhando com cultivares de feijão-comum em diferentes densidades de semeadura em dois locais da região Norte de Minas Gerais verificaram redução do número de vagens por planta, no local onde as condições climáticas eram mais limitantes, fator esse verificado na safra de inverno-primavera do experimento em questão. Também foram encontrados resultados semelhantes a esses por Andrade, Carvalho e Vieira (2006).

O estudo dos efeitos da densidade de semeadura dentro de cada cultivar e safra, revelou que em ambas as safras estudadas, independentemente da cultivar utilizada, o aumento na densidade de semeaduraprovocou redução no número de vagens por planta (Figura 3). Resultados semelhantes já foram observados por Souza (2000), quando estudou populações de 120 a 300 mil plantas ha-1 com as cultivares Carioca e Pérola e por Valério, Andrade e Ferreira (1999), os quais verificaram em três safras, redução linear no número de vagens por planta das cultivares Carioca, Aporé e Pérola quando houve incremento da densidade populacional no intervalo avaliado de 180 a 300 mil plantas ha-1.

No estudo em questão foram avaliados cultivares de diferentes hábitos de crescimento, assim como Alves et al. (2009) que avaliaram as cultivares Radiante, Novo Jalo, Bolinha e Ouro vermelho, os autores observaram redução do número de vagens com aumento da população de plantas. Esse comportamento vem sendo observado desde longa data em diversos trabalhos, principalmente em cultivares que apresentam hábito indeterminado de crescimento, sendo este efeito atribuído ao menor potencial de competição por fotoassimilados nos cultivares de hábito determinado em relação aos de hábito indeterminado, os quais possuem menor capacidade para adaptar a densidades populacionais maiores (MASCARENHAS et al., 1966), provavelmente em razão de maior competição intraespecífica por luminosidade (BENNETT BENNETT; ADAMS; BURGA, 1977) e água, além de nutrientes disponíveis no solo (CÁRDENAS, 1961). 
Figura 3. Número de vagens por planta de quatro cultivares de feijoeiro em função de população de plantas, nas safras da seca (A) e de inverno (B). Janaúba, MG. 2011.
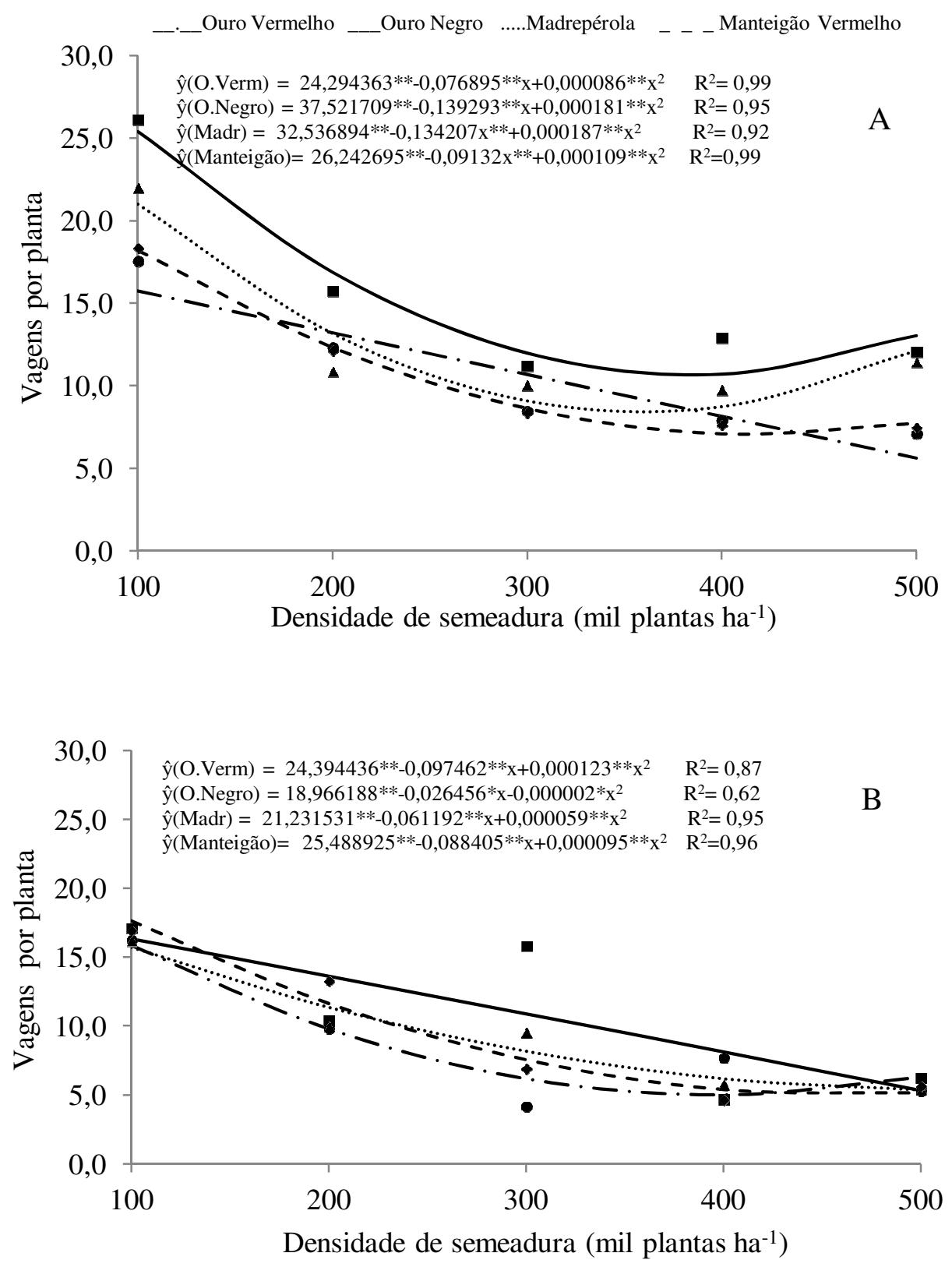

Fonte: Elaboração dos autores.

Corroborando com o estudo em questão, a variável número de vagens por planta é o componente primário que mais se correlaciona com o rendimento de grãos (JAUER et al., 2006; SILVA; LIMA; MENEZES, 2007; SOUZA et al., 2008) e é influenciado por condições ambientais devido ao efeito de plasticidade fenotípica e ambiental do feijoeiro que está relacionada ao maior desenvolvimento da planta e, principalmente, vingamento de flores, quando a planta é submetida à condições de menor competição, conforme destacado por vários pesquisadores (COSTA; KOHAHI-SHIBATA; COLIN, 1983; ARF et al., 1996; JADOSKI et al., 2000; RIBEIRO et al., 2004; SOUZA et al., 2008). 
Os cultivares Ouro Vermelho e Ouro Negro apresentaram maiores valores para o número médio de grãos por vagem do que a cultivar Madrepérola, que por sua vez apresentou valores maiores que os da cultivar Manteigão Vermelho (Tabela 5). Este resultado certamente está relacionado às características intrínsicas dos cultivares.

Tabela 5. Valores médios de grãos por vagem de quatro cultivares de feijoeiro-comum e de duas safras de cultivo. Janaúba, MG. 2011.

\begin{tabular}{lc}
\hline Cultivares & Número de grãos por vagem \\
\hline Ouro vermelho & $4,2 \mathrm{a}$ \\
Ouro Negro & $4,2 \mathrm{a}$ \\
Madrepérola & $3,5 \mathrm{~b}$ \\
Manteigão Vermelho & $2,5 \mathrm{c}$ \\
\hline Safras & Número de grãos por vagem \\
\hline Seca & $3,8 \mathrm{a}$ \\
Inverno & $3,4 \mathrm{~b}$ \\
\hline
\end{tabular}

Médias seguidas de letras diferentes na coluna diferem entre si pelo teste de Tukey a $1 \%$ de probabilidade para cultivares e a $1 \%$ de probabilidade pelo teste F para safras.

Fonte: Elaboração dos autores.

O número médio de grãos por vagem é mais influenciado pelas condições ambientais do que por densidades populacionais, o que explica a não significância para as densidades populacionais estudadas. Outros pesquisadores também já mostraram essa independência (ARF et al., 1996; SHIMADA; ARF; SÁ, 2000; SOUZA et al., 2002; JAUER et al., 2003; SOUZA et al., 2004; JAUER et al., 2006).

Independentemente da cultivar e da densidade de semeadura, o feijoeiro cultivado na safra da seca apresentou maior número de grãos por vagem que o cultivado na safra de inverno (Tabela 5), o que pode ser explicado pelas condições climáticas mais limitantes na safra de inverno em relação a da seca (Figura 1), o que ocasionou chochamento de grãos e abortamento de flores devido a altas temperaturas no período de florescimento.

A massa média de 100 grãos não foi influenciada significativamente pela densidade de semeadura, mostrando que este componente de rendimento é pouco afetado por alterações na população de plantas, conforme verificado por outros autores (SOUZA et al., 2004; JAUER et al., 2006; ALVES et al., 2009; ZILIO et al., 2011). Isto se deve possivelmente por essa característica ser um caráter de herança qualitativa, pouco influenciada pelo ambiente e controlada por poucos genes, conforme constatado por Ramalho, Santos e Zimmermann (1993).

$\mathrm{O}$ desdobramento da interação $\mathrm{Cv}$ x $\mathrm{S}$ revelou que independentemente da cultivar estudado, o feijoeiro semeado na safra da seca apresentou maiores valores de massa de grãos que na outra safra (Tabela 6). Provavelmente esse fato ocorreu devido a fatores climáticos mais limitantes durante a fase de enchimento de grãos na safra de inverno (Figura 1). Outro fator que pode ter contribuído para este resultado é a duração do ciclo fenológico do feijoeiro, que na safra da seca foi de 95 dias, e na safra de inverno foi de 83 dias, garantindo à primeira safra maior período para concentrar fotoassimilados e nutrientes nas plantas e disponibilizá-los para o enchimento dos grãos. 
Tabela 6. Massa média de 100 grãos de quatro cultivares de feijoeiro, em função de duas safras de cultivo. Janaúba, MG, 2011.

\begin{tabular}{lcccc}
\hline \multirow{2}{*}{ Safra } & \multicolumn{4}{c}{ Massa de 100 grãos } \\
\cline { 2 - 5 } & O. vermelho & O. Negro & Madrepérola & Manteigão \\
\hline Seca & $22,5 \mathrm{aB}$ & $21,6 \mathrm{aB}$ & $23,3 \mathrm{aB}$ & $44,3 \mathrm{aA}$ \\
Inverno & $20,8 \mathrm{bAB}$ & $19,0 \mathrm{bB}$ & $21,8 \mathrm{bB}$ & $34,7 \mathrm{bA}$ \\
\hline
\end{tabular}

Dentro de cada fator, médias seguidas por diferentes letras diferem significativamente pelo teste F (safras) ou pelo teste de Tukey (Cultivares), a 1\% de probabilidade. Letras minúsculas comparam as safras, enquanto as maiúsculas comparam as cultivares.

Fonte: Elaboração dos autores.

O estudo dos efeitos das cultivares dentro de cada safra revelou que na safra da seca a cultivar Manteigão Vermelho apresentou maior massa média de grãos que os demais. Entretanto, na safra de inverno, a cultivar Ouro Vermelho obteve massa média de 100 grãos equivalente à obtida pelo Manteigão Vermelho, que, por sua vez, apresentou valores maiores que os obtidos pelos cultivares Ouro Negro e Madrepérola (Tabela 6). A cultivar Manteigão Vermelho pertence ao grupo manteigão, que tem como uma das principais características, possuir sementes grandes, mais pesadas que as demais. Os valores encontrados corroboram com os descritos por Paula Junior et al. (2010).

Avaliando-se o rendimento de grãos no desdobramento da interação $\mathrm{Cv}$ x D x S, constatouse efeito da densidade de semeadura dentro de cada cultivar e safra estudada, e houve diferenças significativas para a cultivar Ouro Negro cultivada na safra da seca (Tabela 7). Neste caso, o aumento da densidade de semeadura incrementou o rendimento de grãos até a densidade de 305 mil plantas ha-1 e redução da produtividade a partir desse ponto (Figura 4). Cobucci, Ferreira e Silva (1996) citam que o espaçamento adequado é aquele que permite cobertura total do solo, quando a cultura atinge seu pleno crescimento vegetativo, devendo ser diferenciado de acordo com as variedades e condições edafoclimáticas. Alves et al. (2009) avaliaram as cultivares Radiante, Novo Jalo, Bolinha e Ouro Vermelho e não observaram diferença significativa para as densidades populacionais de 100 a 500 mil plantas $h^{-1}$ e recomendaram o uso da população de 240 mil plantas ha $^{-1}$ para essas cultivares de diferentes hábitos de crescimento. A não ocorrência de diferenças significativas para as densidades de semeadura nos demais cultivares, certamente está relacionado com o efeito compensatório que ocorreu no número de vagens por planta (Figura 3), que decresceu com o aumento da densidade de semeadura.

O estudo dos efeitos das safras dentro de cada cultivar e densidade de semeadura revelou que a cultivar Ouro Vermelho não apresentou diferenças significativas no rendimento de grãos em relação às safras estudadas, independentemente da densidade de semeadura. Já a cultivar Ouro Negro obteve maior produtividade na safra da seca em relação a safra de inverno nas densidades de plantio de 100, 200 e 500 mil plantas ha ${ }^{-1}$. A cultivar Madrepérola apresentou o mesmo comportamento para as densidades de 400 e 500 mil plantas ha-1, enquanto o Manteigão Vermelho repetiu este resultado nas densidades de 100,300 e 500 mil plantas ha-1. 
Tabela 7. Rendimento de grãos de quatro cultivares de feijão, em função da safra e da densidade de semeadura. Janaúba, MG, 2011.

\begin{tabular}{cccccc}
\hline \multirow{2}{*}{$\begin{array}{c}\text { Densidade } \\
\text { de semeadura }\end{array}$} & Safra & \multicolumn{4}{c}{ Rendimento de grãos } \\
\cline { 3 - 5 } & & O. vermelho & O. Negro & Madrepérola & Manteigão \\
\cline { 3 - 5 } & Seca & $1953 \mathrm{aA}$ & $2516 \mathrm{aA}$ & $1673 \mathrm{aA}$ & $2160 \mathrm{aA}$ \\
\multirow{2}{*}{100} & $1425 \mathrm{aA}$ & $1477 \mathrm{bA}$ & $1722 \mathrm{aA}$ & $1034 \mathrm{bA}$ \\
& Inverno & $2119 \mathrm{aA}$ & $2760 \mathrm{aA}$ & $1786 \mathrm{aA}$ & $2674 \mathrm{aA}$ \\
\multirow{2}{*}{200} & Seca & $1446 \mathrm{aA}$ & $1455 \mathrm{bA}$ & $1637 \mathrm{aA}$ & $2034 \mathrm{aA}$ \\
\hline \multirow{2}{*}{300} & Inverno & $1698 \mathrm{aA}$ & $2654 \mathrm{aA}$ & $1798 \mathrm{aA}$ & $2711 \mathrm{aA}$ \\
& Seca & $1598 \mathrm{aB}$ & $3051 \mathrm{aA}$ & $1463 \mathrm{aB}$ & $1192 \mathrm{bB}$ \\
\hline \multirow{2}{*}{400} & Inverno & $2064 \mathrm{aA}$ & $2603 \mathrm{aA}$ & $2103 \mathrm{aA}$ & $1943 \mathrm{aA}$ \\
& Seca & $2316 \mathrm{aAB}$ & $2390 \mathrm{aB}$ & $1250 \mathrm{bBC}$ & $1238 \mathrm{aC}$ \\
\hline \multirow{2}{*}{500} & Inverno & $1758 \mathrm{aB}$ & $3214 \mathrm{aA}$ & $2507 \mathrm{aAB}$ & $2677 \mathrm{aAB}$ \\
& Seca & $2108 \mathrm{aA}$ & $1826 \mathrm{bA}$ & $1247 \mathrm{bA}$ & $1723 \mathrm{bA}$ \\
\hline
\end{tabular}

Dentro de cada densidade, médias seguidas por diferentes letras diferem significativamente pelo teste $\mathrm{F}$ (safras) ou pelo teste de Tukey (Cultivares), a 5\% de probabilidade. Letras minúsculas comparam as safras, enquanto as maiúsculas comparam as cultivares. Fonte: Elaboração dos autores.

Figura 4. Rendimento de grãos da cultivar Ouro Negro cultivado na safra de inverno, em função de densidades de semeadura. Janaúba, MG, 2011.

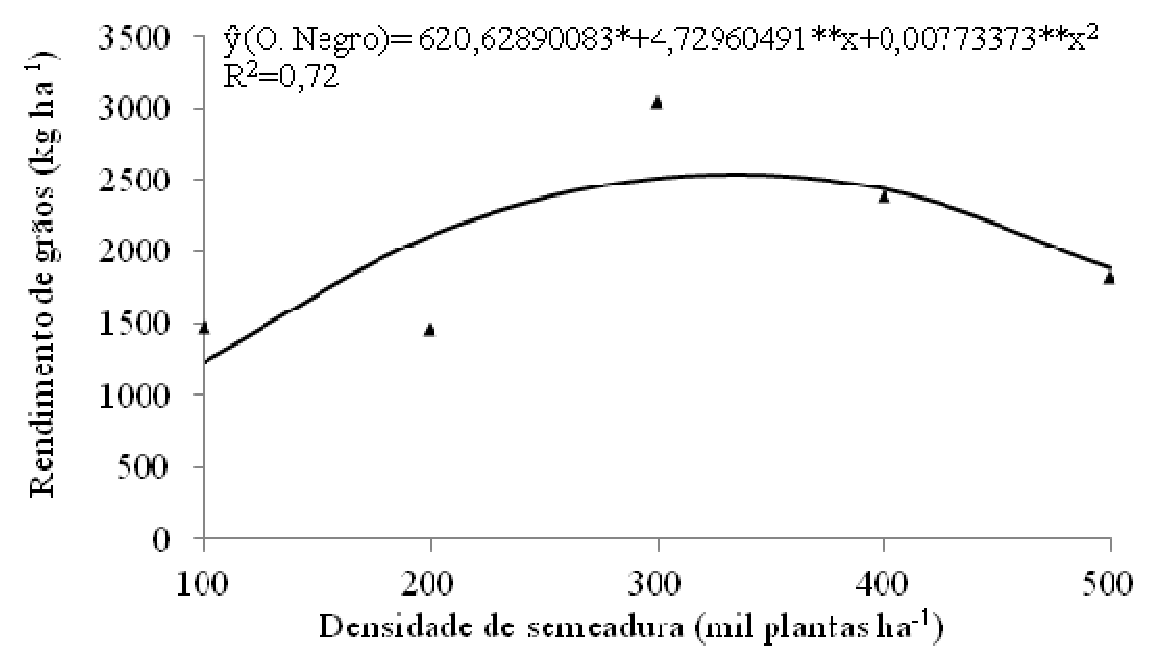

Fonte: Elaboração dos autores.

Estudando-se os efeitos dos cultivares dentro de cada safra e densidade de semeadura, verifica-se que nas densidades de 100 e 200 mil plantas ha-1 não se obteve diferenças significativas para produtividade de grãos entre os cultivares independentemente da safra estudada. Na densidade de semeadura de 300 mil plantas ha ${ }^{-1}$, a cultivar Ouro Negro obteve maior rendimento de grãos que os demais na safra de inverno. Já na densidade de 400 mil plantas $\mathrm{ha}^{-1}$, a cultivar Ouro Negro obteve produtividade equivalente à alcançada pelo Ouro Vermelho e maior que a obtida pelos demais cultivares na safra de inverno. Entretanto, na densidade de 500 mil plantas $\mathrm{ha}^{-1}$, a cultivar Ouro Negro obteve produtividade equivalente às alcançadas pelos cultivares Madrepérola e Manteigão Vermelho e 
maior que a obtida pelo Ouro Vermelho, na safra da seca (Tabela 7).

Os rendimentos obtidos na safra da seca se equiparam a média brasileira no ano de 2011 para a época que foi de $2516 \mathrm{~kg} \mathrm{ha}^{-1}$ e a de Minas Gerais que foi de $2464 \mathrm{~kg} \mathrm{ha}^{-1}$ (CONAB, 2013). Ademais, estes rendimentos já eram esperados, tendo em vista que foi utilizado, na condução dos experimentos, o Nível Tecnológico 3 (NT3) previsto pela $5^{\mathrm{a}}$ aproximação das "Recomendações para o uso de corretivos e fertilizantes para o estado de Minas Gerais" (CHAGAS et al., 1999), no qual a produtividade esperada é de 1800 a $2500 \mathrm{~kg} \mathrm{ha}^{-1}$. A menor produtividade ocorrida na safra de inverno certamente está relacionada às condições climáticas desfavoráveis ao feijoeiro na época de inverno, em que ocorrem altas temperaturas no florescimento e chuvas na colheita (Figura1), acarretando abortamento de flores e chochamento de vagens, reduzindo consequentemente o rendimento de grãos (DICKSON; PETZOLDT, 1989).

Vale ressaltar que apesar das diferenças citadas, os rendimentos de grãos obtidos na maioria das situações viabilizam os quatro cultivares como novas opções para cultivo na região Norte do Estado de Minas Gerais. Aliada a estas produtividades, a boa cotação de preços no mercado de alguns tipos especiais de feijão podem representar para o produtor uma forma de agregar valor ao seu produto e atender a nichos específicos de mercado. Corroborando também com Alves et al. (2009) que encontraram rendimentos de grãos semelhantes para a região Norte de Minas Gerais.

\section{Conclusão}

$\mathrm{O}$ aumento na densidade de semeadura aumenta a mortalidade de plantas e o estande final de plantas, mas reduz o número de vagens por planta.

Com exceção do cultivar Ouro Negro cultivado na safra de inverno, em que o maior rendimento de grãos é obtido com população em torno de 300 mil plantas por hectare, o aumento na densidade de semeadura não interfere na produtividade do feijoeiro.

Independentemente da densidade de semeadura, o feijoeiro cultivado na safra da seca apresenta maior número de grãos por vagem, maior massa média de cem grãos do que o cultivado na safra de inverno.

\section{Agradecimentos}

À Coordenação de Aperfeiçoamento de pessoal de Nível superior (CAPES), por concessão de bolsas ao primeiro ao quarto autores do artigo; à Fundação de amparo à Pesquisa do Estado de Minas Gerais (FAPEMIG) e a Universidade Estadual de Montes Claros (UNIMONTES), pelo apoio financeiro para o desenvolvimento do trabalho.

\section{Referências}

ADAMS, M. W. Basis of yield component compensation in crop plants with special reference to the field bean, (Phaseolus vulgaris L.). Crop Science, Madison, v. 7, $\mathrm{n}$. 5, p. 505-510, 1967.

ALVES, A. F.; ANDRADE, M. J. B.; RODRIGUES, J. R. M.; VIEIRA, N. M. B. Densidades populacionais para cultivares alternativas de feijoeiro no norte de minas gerais. Ciência e Agrotecnologia, Lavras, v. 33, n. 6, p. 1495-1502, 2009.

ANDRADE, M. J. B.; CARVALHO, A. J.; VIEIRA, N. M. B. Exigências edafoclimáticas. In: VIEIRA, C.; PAULA JÚNIOR, T. J.; BORÉM, A. Feijão. 2. ed. Viçosa, MG: UFV, 2006. p. 67-86.

ANDRADE, M. J. B.; RAMALHO, M. A. P.; ABREU, A. F. B. Recomendações para a cultura do feijoeiro em Minas Gerais. Lavras: ESAL, 1992. 12 p.

ARAÚJO, G. A. de A.; FERREIRA, A. C. de B. Manejo do solo e plantio. In: VIEIRA, C.; PAULA JÚNIOR, T. J. DE; BORÉM, A. Feijão. 2. ed. Viçosa: UFV, 2006. p. $87-114$.

ARF, O.; SÁ, M. E.; OKITA, C. S.; TIBA, M. A.; GUERREIRO NETO, G.; OGASSAWARA, O. Efeito de diferentes espaçamentos e densidades de semeadura sobre o desenvolvimento do feijoeiro (Phaseolus vulgaris L.). Pesquisa Agropecuária Brasileira, Brasília, v. 31, n. 9, p. 629-634, 1996. 
BANZATO, D. A.; KRONKA, S. N. Experimentação agrícola. Jaboticabal: FUNEP, 2006. 247 p.

BENNETT, J. P.; ADAMS, M. W.; BURGA, C. Pod yield component variation and intercorrelation in Phaseolus vulgaris L. on affected by planting density. Crop Science, Madison, v. 17, n. 1, p. 73-75, 1977.

BUZETTI, S.; ROMEIRO, P. J. M.; ARF, O.; SÁ, M. E.; GUERREIRO NETO, G. Efeito da adubação nitrogenada em componentes da produção do feijoeiro (Phaseolus vulgaris L.) cultivado em diferentes densidades. Cultura Agronômica, Ilha Solteira, v. 1, n. 1, p. 11-19, 1992.

CÁRDENAS, R. F. La densidad de siembra influye en el rendimento del frijol. Agricultura Técnica em México, Texcoco, v. 12, n. 3, p. 6-8, 1961.

CHAGAS, J. M.; BRAGA, J. M.; VIEIRA, C.; SALGADO, L. T.; JUNQUEIRANETO, A.; ARAÚJO, G. A. A.; ANDRADE, M. J. B.; LANA; R. M. Q.; RIBEIRO, A. C. Feijão. In: RIBEIRO, A. C.; GUIMARÃES, P. T. G.; ALVAREZ, V. V. H. (Ed.). Recomendações para o uso de corretivos e fertilizantes em Minas Gerais: $5^{\text {a }}$ aproximação. Viçosa, MG: Comissão de Fertilidade do Solo do Estado de Minas Gerais, 1999. p. 306-307.

COBUCCI, T.; FERREIRA, F. A.; SILVA, A. A. da. Controle de plantas daninhas. In: ARAUJO, R. S.; RAVA, C. A.; STONE, L. F.; ZIMMERMANN, M. J. de O. (Coord.). Cultura do feijoeiro comum no Brasil. Piracicaba: POTAFOS, 1996. p. 433-464.

COMPANHIA NACIONAL DE ABASTECIMENTO - CONAB. Levantamento de grãos safra2013/2014. Brasília: Sumac, 2013. Disponível em: <http://www. conab.gov.br/conteudos.php? $\mathrm{a}=1253 \& \mathrm{t}=2>$. Acesso em: 10 maio 2014.

COSTA, J. G. C.; KOHAHI-SHIBATA, J.; COLIN, S. M. Plasticidade no feijoeiro comum. Pesquisa Agropecuária Brasileira, Brasília, v. 18, n. 2, p. 159-67, 1983.

DICKSON, M. H.; PETZOLD, R. Heat tolerance and pod set in green beans. Journal of the American Society for Horticultural Science, Alexandria, v. 114, n. 5, p. 833-836, 1989.

EMPRESA BRASILEIRA DE PESQUISA AGROPECUÁRIA-EMBRAPA. BRSMG Madrepérola: cultivar de feijão tipo carioca com escurecimento tardio dos Grãos. Santo Antônio de Goiás: EMBRAPA, 2011. (Comunicado técnico, 200).

. Cultivo do feijoeiro comum. Santo Antônio de Goiás: Embrapa Arroz e Feijão, 2014. Disponível em: <www.cnpaf.embrapa.br>. Acesso em: 10 maio 2014.

. Sistema brasileiro de classificação de solos. 2. ed. Rio de Janeiro: Embrapa Solos, 2006. 306 p.
EMPRESA DE PESQUISA AGROPECUÁRIA DE MINAS GERAIS - EPAMIG. Ouro negro. Belo Horizonte: Epamig, 2012. Disponível em: <http://www. epamig.br/index.php?option=com_content\&task=view $\& \mathrm{id}=200 \&$ Itemid=135> . Acesso em: 12 abr. 2014.

FANCELLI, A. L.; DOURADO NETO, D. Produção de feijão. Piracicaba: Livroceres, 2007. 386 p.

GOULDEN, D. S. Effects of plant population and row spacing on yield and components of yield of Navy beans (Phaseolus vulgaris L.). New Zealand, Journal of Experimental Agriculture, Weilington, v. 4, n. 2, p. 177180, 1976.

HORN, F. L.; SCHUCH, L. O. B.; SILVEIRA, E. P.; ANTUNES, I. F.; VIEIRA, J. C.; MARCHIORO, G.; MEDEIROS, D. F.; SCHWENGBER, J. E. Avaliação de espaçamentos e populações de plantas de feijão visando à colheita mecanizada direta. Pesquisa Agropecuária Brasileira, Brasília, v. 35, n. 1, p. 41-46, 2000.

INSTITUTO BRASILEIRO DE GEOGRÁFIA E ESTATÍSTICA - IBGE. Produção agrícola municipal. 2013. Disponível em: <http://www.sidra.ibge.gov.br> Acesso em: 10 maio 2014.

JADOSKI, S. O.; CARLESSO, R.; WOISCHICK, D.; PETRY, M. T.; FRIZZO, Z. População de plantas e espaçamento entre linhas do feijoeiro irrigado. II: rendimento de grãos e componentes do rendimento. Ciência Rural, Santa Maria, v. 30, n. 4, p. 567-573, 2000.

JAUER, A.; DUTRA, L. M. C.; ZABOT, L.; LUCCA FILHO, O. A.; UHRY, D.; LUDWIG, M. P.; FARIAS, J. R. Comportamento de cultivar pérola de feijoeiro comum (Phaseolus vulgaris L.) em quatro densidades de semeadura na safrinha em Santa Maria-RS. Revista da Faculdade de Zootecnia, Veterinária e Agronomia, Uruguaiana, v. 13, n. 1, p. 12-23, 2006.

JAUER, A.; DUTRA, L. M. C.; ZABOT, L.; LUCCA FILHO, O. A.; LOSEKANN, M. E.; UHRY, D.; STEFANELO, C.; FARIAS, J. R.; LUDWIG, M. P. Análise de crescimento da cultivar de feijão Pérola em quatro densidades de semeadura. Revista da Faculdade de Zootecnia, Veterinária e Agronomia, Uruguaiana, v. 10, n. 1, p. 1-12, 2003.

MASCARENHAS, H. A. A.; IGUE, T.; ALVES, S.; VEIGA, A. A. Espaçamento para o feijão goiano precoce. Bragantia, Campinas, v. 25, n. 41, p. 51-53, 1966.

PAULA JÚNIOR, T. J. de; CARNEIRO, J. E. de S.; VIEIRA, R. F.; ABREU, A. de F. B.; RAMALHO, M. A. P.; PELOSO, M. J. del; TEIXEIRA, H. Cultivares de feijão-comum para Minas Gerais. Belo Horizonte: EPAMIG, 2010. 39 p. 
RAMALHO, M. A. P.; ABREU, A. F. B. Cultivares. In: VIEIRA, C.; PAULA JÚNIOR, T. J.; BORÉM, A. (Ed.). Feijão. 2. ed. Viçosa: UFV, 2006. p. 415-436.

RAMALHO, M. A. P.; SANTOS, J. B., ZIMMERMANN, M. J. de O. Genética quantitativa de plantas autógamas: aplicações ao melhoramento do feijoeiro. Goiânia: UFG, 1993. $271 \mathrm{p}$.

RIBEIRO, N. D.; CARGNELUTTI FILHO, A.; JOST, E.; POERSCH, N. L.; TRENTIN, M. Alterações em caracteres agromorfológicos em função da densidade de plantas em cultivares de feijão. Revista Brasileira de Agrociência, Jaboticabal, v. 10, n. 2, p. 167-173, 2004.

SHIMADA, M. M.; ARF, O.; SÁ, M. E. Componentes do rendimento e desenvolvimento do feijoeiro de porte ereto sob diferentes densidades populacionais. Bragantia, Campinas, v. 59, n. 2, p. 181-187, 2000.

SILVA, A. O.; LIMA, E. A.; MENEZES, H. E. A. Rendimento de grãos de feijão (Phaseolus vulgaris L.), cultivado em diferentes densidades de plantio. Revista das Faculdades Integradas de Bebedouro, Bebedouro, v. 10, n. 3, p. 1-5, 2007.

SOUZA, A. B. Populações de plantas, níveis de adubação e calagem para o feijoeiro (Phaseolus vulgaris L.) num solo de baixa fertilidade. 2000. Tese (Doutorado em Agronomia/Fitotecnia) - Universidade Federal de Lavras, Lavras.

SOUZA, A. B.; ANDRADE, M. J. B.; ALVES. V. G.; CAMPAGNOLI, F. B. Densidades de semeadura, níveis de adubação NPK e calagem para o feijoeiro (cv. Iapar 81) em latossolo argiloso de Ponta Grossa-PR. Semina: Ciências Agrárias, Londrina, v. 25, n. 1, p. 5-12, 2004.
SOUZA, A. B.; ANDRADE, M. J. B.; MUNIZ, J. A.; REIS, R. P. Populações de plantas e níveis de adubação e calagem para o feijoeiro (Phaseolus vulgaris L.) em um solo de baixa fertilidade. Ciência e Agrotecnologia, Lavras, v. 26, n. 1, p. 87-98, 2002.

SOUZA, A. B.; ANDRADE, M. J. B.; VIEIRA, N. M. B.; ALBUQUERQUE, A. Densidades de semeadura e níveis de NPK e calagem na produção do feijoeiro sob plantio convencional, em Ponta Grossa, Paraná. Pesquisa Agropecuária Tropical, Goiânia, v. 38, n. 2, p. 39-43, 2008.

STONE, L. F.; PEREIRA, A. L. Sucessão arroz-feijão irrigados por aspersão. Efeitos de espaçamento entre linhas, adubação e cultivar na produtividade e nutrição do feijoeiro. Pesquisa Agropecuária Brasileira, Brasília, v. 29, n. 4, p. 521-533, 1994.

TAIZ, L.; ZEIGER, E. Plant phisiology. 5. ed. Porto Alegre: Artmed, 2013. 954 p.

VALÉRIO, C. R.; ANDRADE, M. J. B.; FERREIRA, D. F. Comportamento das cultivares de feijão Aporé, Carioca e Pérola em diferentes populações de plantas e espaçamento entre linhas. Ciência e Agrotecnologia, Lavras, v. 23, n. 3, p. 515-528, 1999.

ZILIO, M.; COELHO, C. M. M.; SOUZA, C. A.; SANTOS, J. C. P.; MIQUELLUTI, D. J. Contribuição dos componentes de rendimento na produtividade de genótipos crioulos de feijão (Phaseolus vulgaris L.). Revista Ciência e Agrotecnologia, Lavras, v. 42, n. 2, p. 429-438, 2011. 